\title{
RNF43 Protein Variant
}

National Cancer Institute

\section{Source}

National Cancer Institute. RNF43 Protein Variant. NCI Thesaurus. Code C146971.

A variation in the amino acid sequence for E3 ubiquitin-protein lig ase RNF43. 